\title{
Excess mortality among the elderly in 12 European countries, February and March 2012
}

A Mazick (maz@ssi.dk) ${ }^{1}$, B Gergonne ${ }^{2}$, J Nielsen ${ }^{1}$, F Wuillaume ${ }^{3}$, M J Virtanen $^{4}$, A Fouillet ${ }^{5}$, H Uphoff ${ }^{6}$, T Sideroglou ${ }^{7}$, A Paldy ${ }^{8}$,

A Oza9, B Nunes ${ }^{10}$, V M Flores-Segoviaa ${ }^{11}$, C Junker ${ }^{12}$, S A McDonald ${ }^{13}$, H K Green ${ }^{14}$, R Pebody ${ }^{14}$, K Mølbak ${ }^{1}$

1. Statens Serum Institut, Copenhagen, Denmark

2. The National Board of Health and Welfare, Stockholm, Sweden

3. Scientific Institute of Public Health, Brussels, Belgium

4. National Institute for Health and Welfare, Helsinki, Finland

5. French Institute for Public Health Surveillance (Institut de Veille Sanitaire, InVS), Saint-Maurice, France

6. Hesse State Health Office, Dillenburg, Germany

7. Hellenic Centre for Disease Control and Prevention, Athens, Greece

8. Hungary National Institute of Environmental Health, Budapest, Hungary

9. Health Protection Surveillance Centre, Dublin, Ireland

10. Instituto Nacional de Saúde Dr. Ricardo Jorge, Lisbon, Portugal

11. Instituto de Salud Carlos III, Madrid, Spain

12. Federal Statistical Office, Neuchâtel, Switzerland

13. National Institute for Public Health and the Environment (RIVM), Bilthoven, the Netherlands

14. Health Protection Agency, Colindale, United Kingdom

Citation style for this article:

Mazick A, Gergonne B, Nielsen J, Wuillaume F, Virtanen MJ, Fouillet A, Uphoff H, Sideroglou T, Paldy A, Oza A, Nunes B, Flores-Segovia VM, Junker C, McDonald SA, Green HK, Pebody R, Mølbak K. Excess mortality among the elderly in 12 European countries, February and March 2012 . Euro Surveill. $2012 ; 17(14)$ : pii=20138. Available online: http://www.eurosurveillance.org/ViewArticle.aspx?Articleld=20138

In February and March 2012, excess deaths among the elderly have been observed in 12 European countries that carry out weekly monitoring of all-cause mortality. These preliminary data indicate that the impact of influenza in Europe differs from the recent pandemic and post-pandemic seasons. The current excess mortality among the elderly may be related to the return of influenza $A\left(\mathrm{H}_{3} \mathrm{~N}_{2}\right)$ virus, potentially with added effects of a cold snap.

In most winter seasons, excess all-cause mortality among the elderly is observed in Europe. The extent of this excess varies considerably between seasons and between countries [1-5]. Most often, this excess has been attributed to seasonal influenza illness, especially in seasons dominated by $\mathrm{A}\left(\mathrm{H}_{3} \mathrm{~N}_{2}\right)$ virus subtype, but other factors such as cold weather and infections resulting from other respiratory agents also play a role [1-8].

Since the beginning of February 2012, an increased number of excess deaths among the elderly has been observed in a number of European countries that carry out weekly monitoring of all-cause age-specific mortality.

The aim of this article is to describe the occurrence of this recently observed excess mortality in Europe and consider potential explanations in order to encourage other countries to assess their situation and share experiences.

\section{Monitoring all-cause mortality in Europe}

Since autumn 2009, monitoring of weekly all-cause mortality has been carried out in up to 16 countries across Europe. This was initially part of the European monitoring of excess mortality for public health action (EuroMOMO), a project funded first by the European Union Health Programme [9] and later, European mortality monitoring received funding from the European Centre for Disease Prevention and Control (ECDC). The public health value of the project was underlined in the 2009 influenza pandemic, when these excess mortality outputs became important for European risk assessments [10-12].

A common statistical algorithm is used in EuroMOMOparticipating countries to generate weekly indicators for age group-specific excess mortality that are comparable across countries. The algorithm is a time-series Poisson regression model with number of weekly deaths as a dependent variable adjusting for trend and seasonal variation. The algorithm also corrects for the delay observed between data collection and data processing in each country.

The main indicators generated are:

- total weekly number of deaths corrected for delay in registration;

- expected weekly number of deaths (baseline);

- weekly number of excess deaths (defined as observed number minus the expected number of deaths);

- standard deviation around the baseline (z-score);

- total mortality (all age groups) and mortality stratified into age groups ( $\langle 5,5-14,15-64$ and $\geq 65$ years). 
Standard deviation scores (z-scores) are used to standardise outputs and enable comparison of mortality patterns between different populations and between different time periods. Excess mortality above two $z$-scores from the baseline is considered above the normal level of the standard variation of data. Details of the EuroMOMO algorithm can be found elsewhere [13].

Data outputs from individual partner countries are compiled by the Statens Serum Institut in Denmark. Data analysed for this paper included all-cause mortality from week 1 (2 January) up to and including week 11 (18 March) 2012. A total of 14 countries submitted data: Belgium, Denmark, Finland, France, Germany (Hessen region), Greece (regions of Athens, Keratsini, Magnisia and Kerkira), Hungary, Ireland, the Netherlands, Portugal, Spain, Sweden, Switzerland and the United Kingdom (UK) (England and Wales).

Data on influenza activity were derived from the ECDC weekly influenza surveillance overview [14], EuroFlu [15] and from personal communication with national influenza surveillance representatives. Increased influenza activity was defined as medium or high influenza intensity, as reported through these channels.

\section{Results}

All-cause mortality among the elderly (individuals aged $\geq 65$ years) has been above two z-scores from the baseline for two consecutive weeks or more in Belgium, Portugal and Spain from week 5 , in France and the Netherlands from week 6, in Finland, Hungary, Sweden and Switzerland from week 7 . In the UK mortality among the elderly has been above $2 \mathrm{z}$-scores in weeks 7-8 and 11-12. Ireland reported a one-week peak of a z-score above 2 in week 9 and Greece in week 10. Denmark and Germany reported no excess mortality.

Although data from week 11 may be influenced by reporting delay, it appears that mortality has peaked and is now decreasing in Belgium, Finland, France, Portugal, Spain, Sweden and the Netherlands.

In Spain and Portugal, mortality has been above two $z$-scores from the baseline for two and three weeks, respectively, in the age group 15-64 years of age. Otherwise, there has been no sign of excess mortality in other age groups studied ( $0-4,5-14$ years).

In Portugal, Spain, France, Switzerland, Finland, Hungary, Ireland and Greece excess mortality among the elderly coincided with or followed after reported increased influenza activity (Figure 2). In Belgium, Sweden and the Netherlands, excess mortality seemed to precede, at least partly, reported increased influenza activity. In the UK, there was excess mortality but no reported increased influenza activity and in Germany, there was reported increased influenza activity but no excess mortality. Denmark, which has observed no excess mortality to date, reported no increased influenza activity. Among the countries that observed excess mortality, only the UK did not see medium or high influenza activity at least in parts of the same time period.

\section{Discussion}

As in previous winter seasons, a number of European countries are experiencing increased mortality in the elderly population. Unlike the past two seasons, the excess mortality this year coincided in most countries with late increased influenza activity. An impact of influenza on the elderly is not unexpected, as this year is dominated by influenza $A\left(\mathrm{H}_{3} \mathrm{~N}_{2}\right)$ : according to the ECDC weekly influenza surveillance overview of 30 March 2012, 95\% of the influenza A viruses detected from sentinel and non-sentinel sources this season were type $\mathrm{H}_{3} \mathrm{~N}_{2}$ [17]. In contrast, influenza $\mathrm{A}\left(\mathrm{H}_{1} \mathrm{~N}_{1}\right)$ pdmog was the prevailing type in the past two years. The pandemic virus more or less spared the elderly - although some countries, such as the UK, did observe excess mortality in middle-aged adults likely to be attributable to influenza $A\left(\mathrm{H}_{1} \mathrm{~N}_{1}\right)$ pdmog activity $[4,10,18]$.

There are, at present, differences in observed excess mortality between European countries using the EuroMOMO algorithm. The available influenza data do not offer an exhaustive explanation for these differences. In most countries, excess mortality coincided or followed after reported increases in influenza activity. This pattern has been regularly observed in the pre-pandemic years $[1-5,8]$ and corroborates the association of influenza (in particular influenza $A\left(\mathrm{H}_{3} \mathrm{~N}_{2}\right)$ ) and excess deaths in the elderly. In particular, in the present season there are reports that some of these influenza $\mathrm{A}\left(\mathrm{H}_{3} \mathrm{~N}_{2}\right)$ viruses are an imperfect match with the $A\left(\mathrm{H}_{3} \mathrm{~N}_{2}\right)$ strain included in the current vaccine; however, the contribution of this to the epidemiology of the observed excess mortality is unclear at this stage [19].

The data presented in Figure 2 suggest that the overlap between influenza activity and excess mortality was discordant in a few countries. There are several possible explanations for this observation. Firstly, the different patterns may suggest that other factors contribute to the occurrence of excess mortality. Indeed, there was a cold spell across Europe during weeks 4 to 6 this year throughout Europe, which might add to excess mortality in some countries, but not in others. It is well known that periods of extreme cold are associated with excess mortality $[1,4,7,20,21]$. In Spain, Belgium and the Netherlands, excess mortality could be observed before influenza transmission increased: we hypothesise that the cold spell could have been a contributing factor in those countries.

Secondly, the current definition of increased national influenza activity is based on a risk assessment by each European country. As a consequence, there are subjective differences in how this is interpreted. This may also partially explain the apparent discordance between observed excess mortality and reported level 


\section{FIGURE 1}

Weekly mortality among those aged $\geq 65$ years in 14 EuroMOMO countries as standardised deviations from the baseline (z-scores), week 7 2009-week 112012 (9 Feb 2009-18 March 2012)

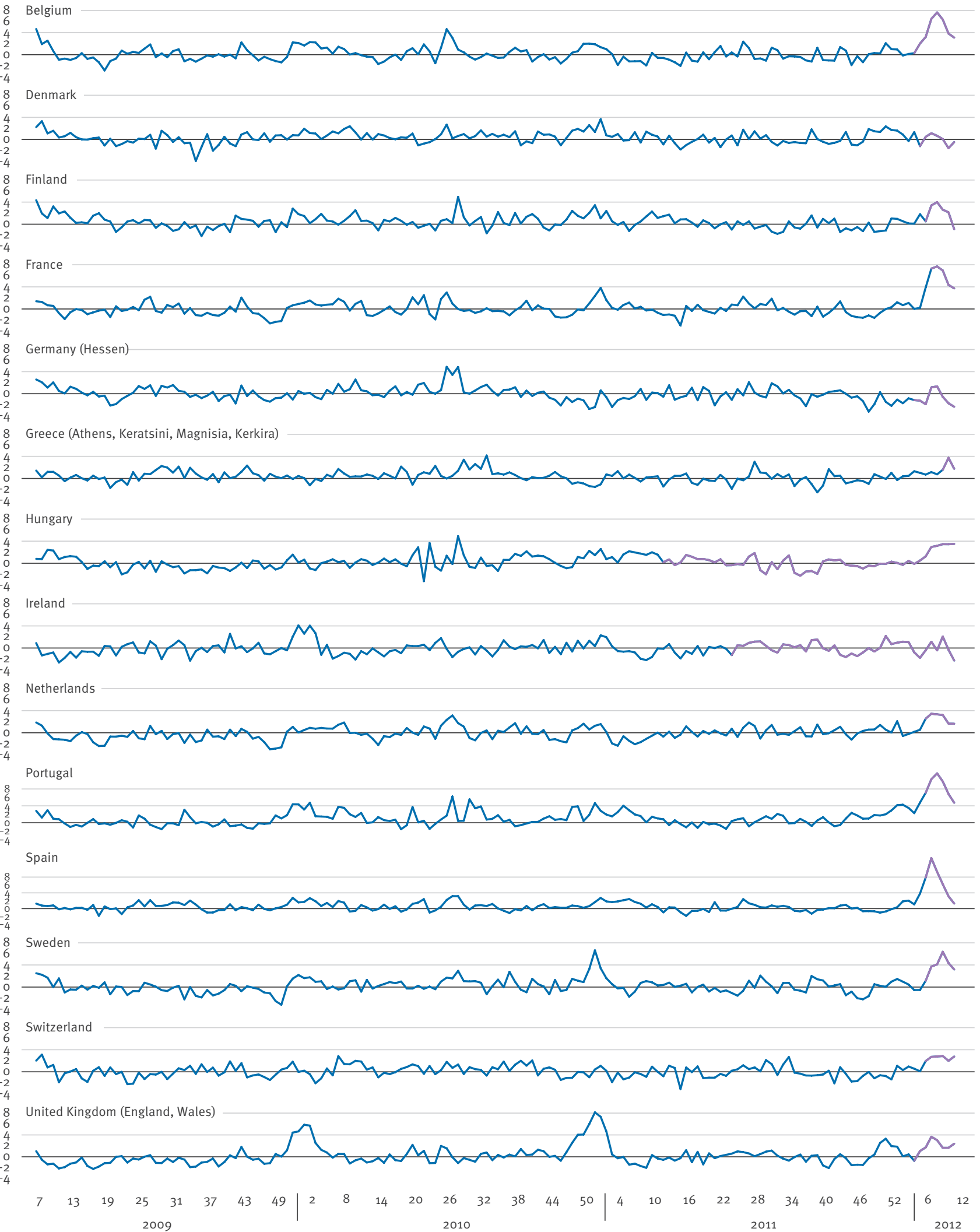


of influenza activity seen in some counties. It highlights the importance of developing more standardised objective measures of influenza activity. Finally, it is possible that infections other than influenza may contribute to excess mortality among the elderly in some countries.

The occurrence of potential risks at similar times - i.e. the cold snap and increased influenza activity - this winter season highlights the difficulty of disentangling the effects of different causes of excess mortality. Studies have shown that multivariate regression models can be successfully used to better quantify the impact of mortality risks such as influenza viruses, other respiratory viruses as well as extreme weather conditions $[1,4,22,23]$.

In order to assess the public health impact of influenza at the population level, it is important to develop a common European approach to estimate the number of excess deaths associated with influenza. By including relevant and standardised indicators of influenza

\section{FIGURE 2}

Excess mortality above two z-scores above baseline among those aged $\geq 65$ years and increased influenza intensity, in 14 EuroMOMO countries, by week, weeks 1-11

(2 January-18 March) 2012

\begin{tabular}{|c|c|c|c|c|c|c|c|c|c|c|c|}
\hline \multirow{2}{*}{ Country } & \multicolumn{11}{|c|}{ Week } \\
\hline & 1 & 2 & 3 & 4 & 5 & 6 & 7 & 8 & 9 & 10 & 11 \\
\hline \multicolumn{12}{|l|}{ Portugal $^{a}$} \\
\hline \multicolumn{12}{|l|}{ Spain } \\
\hline \multicolumn{12}{|l|}{ France } \\
\hline \multicolumn{12}{|l|}{ Switzerland } \\
\hline \multicolumn{12}{|l|}{ Finland } \\
\hline \multicolumn{12}{|l|}{ Hungary } \\
\hline \multicolumn{12}{|l|}{ Ireland } \\
\hline \multicolumn{12}{|l|}{ Greece $^{\mathrm{b}}$} \\
\hline \multicolumn{12}{|l|}{ Germany $^{c}$} \\
\hline \multicolumn{12}{|l|}{ Belgium } \\
\hline \multicolumn{12}{|l|}{ Netherlands } \\
\hline \multicolumn{12}{|l|}{ Sweden } \\
\hline United Kingdom ${ }^{d}$ & & & & & & & & & & & \\
\hline
\end{tabular}

Excess mortality above 2 z-scores

Influenza intensity medium or high activity, virological data, vaccination data, climatic data and other respiratory infection data, it will be possible to perform a timely regression analysis to estimate excess mortality associated with influenza. We recommend that a standard approach should be developed with the results summarised at the end of the influenza season when final data are available. However, it is also important on an ongoing basis to collate, analyse, interpret and disseminate mortality data in order to inform public health actions. As cause-of-death in most countries will not be available in a timely fashion, this has to be carried out based on all-cause mortality data, and has to be interpreted in a qualitative method as in the present paper. On the basis of our preliminary data, we hypothesise that the epidemiology of the impact of influenza in Europe differs in the 2011/12 season from the recent pandemic and post-pandemic seasons, with excess mortality in the elderly caused by the return of influenza $\mathrm{A}\left(\mathrm{H}_{3} \mathrm{~N}_{2}\right)$ virus, potentially with the added effects of a cold snap.

\section{Acknowledgments}

The EuroMOMO network has received financial support from DG Sanco (Directorate-General for Health and Consumer Protection) (1 February 2008 to 30 April 2011) and from ECDC (1 October 2011 to 31 January 2012).

\section{References}

1. Nielsen J, Mazick A, Glismann S, Mølbak K. Excess mortality related to seasonal influenza and extreme temperatures in Denmark, 1994-2010. BMC Infect Dis. 2011;11:350.

2. Jansen AG, Sanders EA, Hoes AW, van Loon AM, Hak E. Influenza- and respiratory syncytial virus-associated mortality and hospitalisations. Eur Respir J. 2007;30(6):1158-66.

3. Nunes B, Viboud C, Machado A, Ringholz C, Rebelo-deAndrade $\mathrm{H}$, Nogueira $\mathrm{P}$, et al. Excess mortality associated with influenza epidemics in Portugal, 1980 to 2004. PLoS One. 2011;6(6):e20661

4. Hardelid P, Pebody R, Andrews N. Mortality caused by influenza and respiratory syncytial virus by age group in England and Wales 1999-2010. Influenza Other Respi Viruses. 2012 Mar 9. doi: 10.1111/j.1750-2659.2012.00345.x. [Epub ahead of print].

5. Rizzo C, Bella A, Viboud C, Simonsen L, Miller MA, Rota MC, et al. Trends for influenza-related deaths during pandemic and epidemic seasons, Italy, 1969-2001. Emerging Infect Dis. 2007;13(5):694-9.

6. Cold exposure and winter mortality from ischaemic heart disease, cerebrovascular disease, respiratory disease, and all causes in warm and cold regions of Europe. The Eurowinter Group. Lancet. 1997;10;349(9062):1341-6.

7. Donaldson GC, Keatinge WR. Excess winter mortality: influenza or cold stress? Observational study. BMJ. 2002;324(7329):89-90.

8. Thompson WW, Shay DK, Weintraub E, Brammer L, Cox $\mathrm{N}$, Anderson LJ, et al. Mortality associated with influenza and respiratory syncytial virus in the United States. JAMA. 2003;289(2):179-86.

9. EuroMOMO. [Accessed 29 Mar 2012]. Available from: http:// www.euromomo.eu/

10. Hardelid P, Andrews N, Pebody R. Excess mortality monitoring in England and Wales during the influenza $A\left(\mathrm{H}_{1} \mathrm{~N}_{1}\right) 2009$ pandemic. Epidemiol Infect. 2011;139(9):1431-9.

11. Mazick A, Gergonne B, Wuillaume F, Danis K, Vantarakis A, Uphoff $\mathrm{H}$, et al. Higher all-cause mortality in children during autumn 2009 compared with the three previous years: pooled results from eight European countries. Euro Surveill. 2010;15(5): pii=19480. Available from: http://www. eurosurveillance.org/ViewArticle.aspx?Articleld $=19480$

Mortality data from [16]

Athens, Keratsini, Magnisia, Kerkira.

Hessen.

England, Wales. 
12. Nicoll A, Ammon A, Amato Gauci A, Ciancio B, Zucs P, Devaux I, et al. Experience and lessons from surveillance and studies of the 2009 pandemic in Europe. Public Health. 2010;124(1):14-23.

13. Gergonne B, Mazick A, O’Donnell J, Oza A, Cox B, Wuillaume $F$, et al. A European algorithm for a common monitoring of mortality across Europe. Work package 7 report. Copenhagen: Statens Serum Institut; 2011. Available from: http://www. euromomo.eu/results/pdf/wp7_finalreport.pdf

14. European Centre for Disease Prevention and Control (ECDC). Weekly influenza surveillance overview (WISO). Stockholm: ECDC. [Accessed 29 Mar 2012]. Available from: http:// ecdc.europa.eu/en/healthtopics/seasonal_influenza/ epidemiological_data/pages/weekly_influenza_surveillance_ overview.aspx

15. WHO/Europe influenza surveillance (EuroFlu.org). Copenhagen: World Health Organization Regional Office for Europe. [Accessed 29 Mar 2012]. Available from: http://www.euroflu. org/

16. Gripe. Vigilância epidemiológica semanal, clínica e laboratorial. Portugal, época 2011/2012. Semana 12 - de $19 / 03 / 2012$ a 25/03/2012. Atividade gripal moderada. Incidência da síndroma gripal com tendência decrescente. Predominância do vírus $\mathrm{A}\left(\mathrm{H}_{3}\right)$. Mortalidade por "todas as causas" com valor de acordo com o esperado. [Influenza. Weekly epidemiological, clinical and laboratory surveillance. Portugal, season 2011-2012 - from 19.03.2012 to 25.03.2012. Medium influenza activity. Influenza-like illness incidence with decreasing trend. Observed all causes deaths according with the expected]. [Accessed 3 Apr 2012]. Portuguese. Available from: http://www.insa.pt/sites/INSA/Portugues/Documents/ Gripe2.pdf

17. European Centre for Disease Prevention and Control (ECDC). Weekly influenza surveillance overview. 30 March 2012. Stockholm: ECDC. [Accessed 3 Apr 2012]. Available from: http://ecdc.europa.eu/en/publications/Publications/120330_ SUR Weekly_Influenza_Surveillance_Overview.pdf

18. Viboud C, Miller M, Olson D, Osterholm M, Simonsen L. Preliminary estimates of mortality and years of life lost associated with the $2009 \mathrm{~A} / \mathrm{H}_{1} \mathrm{~N}_{1}$ pandemic in the US and comparison with past influenza seasons. PLoS Curr. 2010; RRN1153.

19. European Centre for Disease Prevention and Control (ECDC). Weekly influenza surveillance overview. 23 March 2012. Main surveillance developments in week 11/2012 (12-18 March 2012). Stockholm: ECDC. [Accessed 30 Mar 2012]. Available from: http://ecdc.europa.eu/en/publications/ Publications/120323_SUR_Weekly_Influenza_Surveillance_ Overview.pdf

20. Huynen MM, Martens P, Schram D, Weijenberg MP, Kunst $A E$. The impact of heat waves and cold spells on mortality rates in the Dutch population. Environ Health Perspect. 2001;109(5):463-70.

21. Kysely J, Pokorna L, Kyncl J, Kriz B. Excess cardiovascular mortality associated with cold spells in the Czech Republic. BMC Public Health. 2009;9:19.

22. Cox B, Wuillaume F, Van Oyen H, Maes S. Monitoring of allcause mortality in Belgium (Be-MOMO): a new and automated system for the early detection and quantification of the mortality impact of public health events. Int J Public Health. 2010;55(4):251-9.

23. Wijngaard CC, Asten L, Koopmans MP, Pelt W, Nagelkerke NJ, Wielders CC, et al. Comparing pandemic to seasonal influenza mortality: moderate impact overall but high mortality in young children. PLoS One. 2012;7(2):e31197. 